\title{
Correction to: Superficial residual stress, microstructure, and efficiency in similar joints of AA2024-T3 and AA7475-T761 aluminum alloys formed by friction stir welding
}

\author{
João Paulo Buoro Perandini ${ }^{1}$. Ed Claudio Bordinassi ${ }^{1,2}$ - Mario Henrique Fernandes Batalha ${ }^{3}$. \\ André Ferrara Carunchio ${ }^{3} \cdot$ Sergio Delijaicov ${ }^{1}$
}

Published online: 18 June 2021

(C) Springer-Verlag London Ltd., part of Springer Nature 2021

Correction to: The International Journal of Advanced Manufacturing Technology

https://doi.org/10.1007/s00170-021-07238-5

The original article contained a mistake.

The Figs. 14 and 15 are the same. The Fig. 14 needs to be changed to:

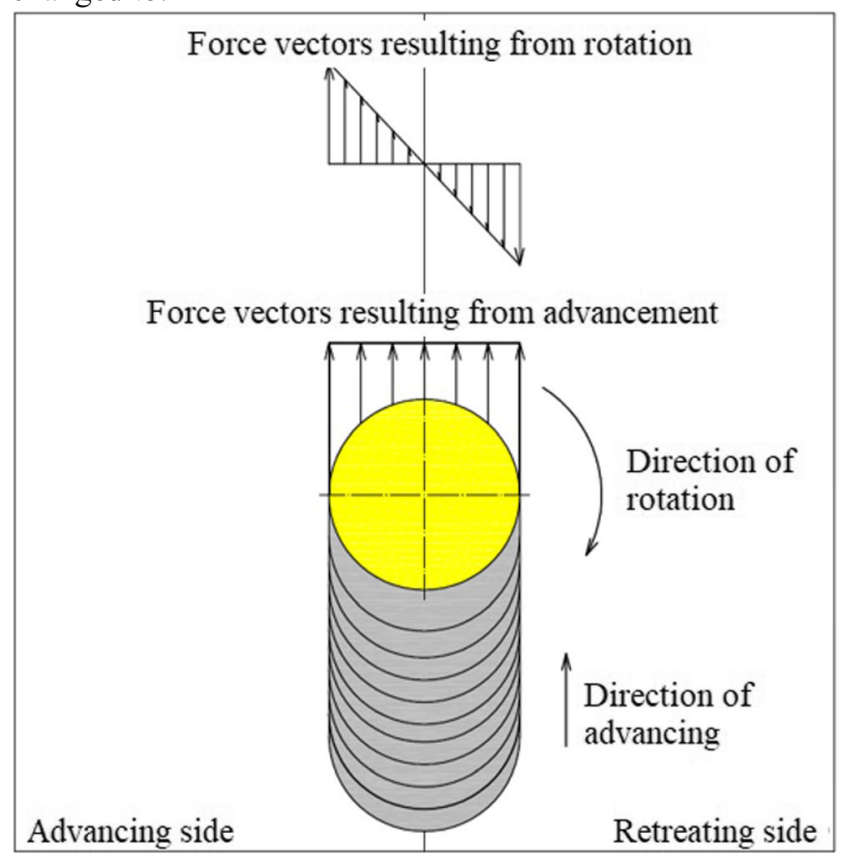

Fig. 14 Vector field of forces during welding, without scale

The online version of the original article can be found at https://doi.org/ $10.1007 / \mathrm{s} 00170-021-07238-5$

Ed Claudio Bordinassi

ecb@maua.br

Department of Mechanical Engineering, University Center of FEI, Av. Humberto de Alencar Castelo Branco, São Bernardo do Campo, SP 3972, Brazil
2 Department of Mechanical Engineering, University Center of Maua, Institute of Technology, Praça Maua, 01, São Caetano do Sul, SP, Brazil

Lightweight Structures Laboratory of IPT, São José dos Campos, SP, Brazil 
The Figs. 16 and 17 are the same. The Fig. 16 needs to be changed to:
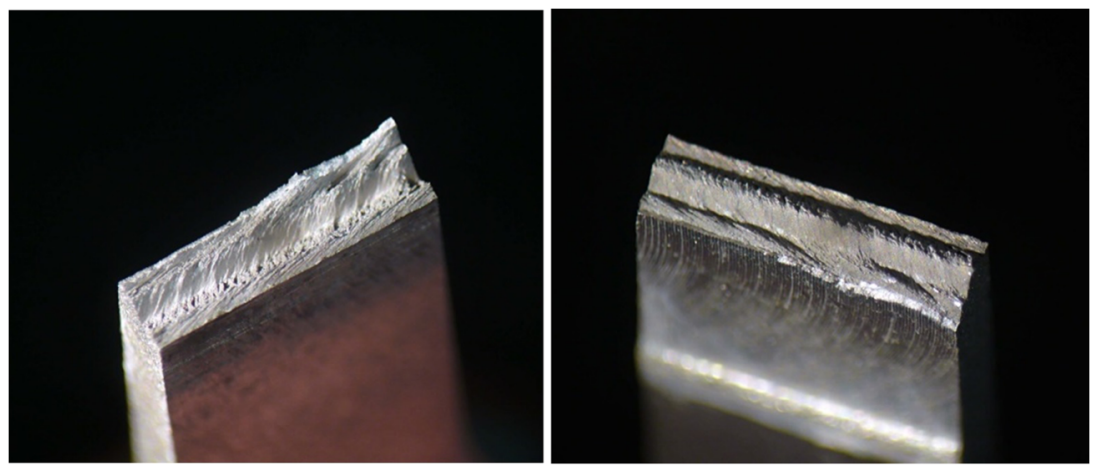

Fig. 16 Specimen after tensile test illustrating the failure region

The original article has been corrected.

Publisher's note Springer Nature remains neutral with regard to jurisdictional claims in published maps and institutional affiliations. 